\title{
BiCuSeO Thermoelectrics: An Update on Recent Progress and Perspective
}

\author{
Xiaoxuan Zhang, Cheng Chang, Yiming Zhou and Li-Dong Zhao * \\ School of Materials Science and Engineering, Beihang University, Beijing 100191, China; \\ zhang1346795@126.com (X.Z.); ccbuaa523@163.com (C.C.); aliex_7@163.com (Y.Z.) \\ * Correspondence: zhaolidong@buaa.edu.cn
}

Academic Editor: Paz Vaqueiro

Received: 26 December 2016; Accepted: 14 February 2017; Published: 17 February 2017

\begin{abstract}
A BiCuSeO system has been reported as a promising thermoelectric material and has attracted great attention in the thermoelectric community since 2010. Recently, several remarkable studies have been reported and the $\mathrm{ZT}$ of $\mathrm{BiCuSeO}$ was pushed to a higher level. It motivates us to systematically summarize the recent reports on the $\mathrm{BiCuSeO}$ system. In this short review, we start with several attempts to optimize thermoelectric properties of BiCuSeO. Then, we introduce several opinions to explore the origins of low thermal conductivity for $\mathrm{BiCuSeO}$. Several approaches to enhance thermoelectric performance are also summarized, including modulation doping, introducing dual-vacancies, and dual-doping, etc. At last, we propose some possible strategies for enhancing thermoelectric performance of $\mathrm{BiCuSeO}$ in future research.
\end{abstract}

Keywords: $\mathrm{BiCuSeO}$; thermoelectric; electrical conductivity; Seebeck coefficient; thermal conductivity

\section{Introduction}

Thermoelectric (TE) materials have been widely developed to provide a direct solution for energy conversion between electricity and heat. As one of the most promising thermoelectric systems, the BiCuSeO family was first reported in 2010 [1] and has attracted ever-increasing attention in recent years [2-10].

$\mathrm{BiCuSeO}$ crystallizes in a layered $\mathrm{ZrCuSiAs}$ structure type with space group $\mathrm{P} 4 / \mathrm{nmm}$ [11]. The crystal structure of $\mathrm{BiCuSeO}$ is formed by fluorite $\left(\mathrm{Bi}_{2} \mathrm{O}_{2}\right)^{2+}$ layers and anti-fluorite $\left(\mathrm{Cu}_{2} \mathrm{O}_{2}\right)^{2-}$ layers which stacking along the $c$-axis. $\left(\mathrm{Bi}_{2} \mathrm{O}_{2}\right)^{2+}$ layers act as carrier reservoir while $\left(\mathrm{Cu}_{2} \mathrm{O}_{2}\right)^{2-}$ layers are responsible for transporting carriers [1]. Pristine $\mathrm{BiCuSeO}$ is a $p$-type semiconductor, in which holes are generated from either $\mathrm{Cu}$ - or Bi-vacancies which participate in transportation in the conductive $\left(\mathrm{Cu}_{2} \mathrm{O}_{2}\right)^{2-}$ layers. Due to its layered structure, $\mathrm{BiCuSeO}$ shows anisotropic transport behaviors along in-plane and out-plane directions for both electrical and thermal conductivity. The electrical and the thermal transport properties along the in-plane direction outperform those along the out-plane direction. However, the Seebeck coefficient is isotropic [7].

Compared with the state-of-the-art TE materials including lead and tin chalcogenides [12-18], $\mathrm{Bi}_{2} \mathrm{Te}_{3}$-based systems [19-23], skutterudites [24-29], etc. BiCuSeO features lower-cost and non-toxic elements and better thermal stability in the medium temperature range. Additionally, due to the large Seebeck coefficient, low thermal conductivity and relatively low electrical conductivity, the dimensionless thermoelectric figure-of-merit $(Z T)$ value of the BiCuSeO system has boosted to the maximum $Z T$ of 1.5 [10], from the initial 0.76 for Sr-doped samples [1], in the past six years. The obvious enhancement in $Z T$ subverts the general opinions that thermoelectric oxides usually have low $Z T$ values due to poor electrical conductivity and high thermal conductivity.

Since the review paper summarized by Zhao et al. in 2014 [11], a lot of new achievements have been obtained in $\mathrm{BiCuSeO}$ system, which motivate us to update these results to show the 
current progress in $\mathrm{BiCuSeO}$ system. In this review, we summarize the latest attempts and methods on optimizing thermoelectric properties of $\mathrm{BiCuSeO}$ system, and then introduce several opinions on the origins of low thermal conductivity. Additionally, some typically promising approaches including modulation doping [8], dual-vacancies [9] and dual-doping [10] are summarized. In the end, we propose some outlooks and perspectives for future research.

\section{A Short Review for Various Attempts to Optimize BiCuSeO System}

\subsection{Enhancing Thermoelectric Properties through Doping and Compositing}

It is well known that the thermal conductivity of BiCuSeO is impressively low. Thus, most recent attention has focused on improving the electrical transport properties through various attempting approaches. For instance, considering the carrier concentration of undoped $\mathrm{BiCuSeO}$ is as low as $\sim 1 \times 10^{18} \mathrm{~cm}^{-3}$ [11], the most general approach is to enhance the carrier concentration by doping on $\mathrm{Bi}$ sites or $\mathrm{Cu}$ sites. Indeed, the carrier concentration was increased by alkaline earth elements $\mathrm{M}^{2+}(\mathrm{M}=\mathrm{Mg}, \mathrm{Ca}, \mathrm{Sr}$, and $\mathrm{Ba})$ doping [1,2,4,30]. Besides these alkaline-earth elements, $\mathrm{Ag}, \mathrm{Na}, \mathrm{La}$, $\mathrm{Zn}, \mathrm{Cd}$, and $\mathrm{S}$ doping in $\mathrm{BiCuSeO}$ [31-38] were reported and exhibited potential performance in medium temperature range. In addition, the compositing with high electrical conductive phases $\left(\mathrm{La}_{0.8} \mathrm{Sr}_{0.2} \mathrm{CoO}_{3}\right.$ [39], $\mathrm{Cu}_{2} \mathrm{Se}$ [40]) could successfully improve the thermoelectric properties of pristine $\mathrm{BiCuSeO}$ through enhancing the electrical conductivity.

\subsection{Developing Less Time-Consuming Methods}

Initially, it was suggested that polycrystalline BiCuSeO compounds should be synthesized through a multi-step solid-state reaction (SSR), which is complicated and time-consuming. Therefore, any facile or time-saving methods are advanced for future scale-up of resultant products. Ren et al. [41] explored the synthesis of polycrystalline $\mathrm{Bi}_{1-x} \mathrm{~Pb}_{x} \mathrm{CuSeO}$ through an ultrafast self-propagating high-temperature synthesis (SHS) method. In addition, Yang et al. [42] adopted SHS to synthesize polycrystalline $\mathrm{Bi}_{0.94} \mathrm{~Pb}_{0.06} \mathrm{CuSeO}$ and further explored the thermodynamic reaction mechanism in details. It was confirmed that the entire reaction process consists of four parts. External heating initiated two rapid SHS reactions $\left(2 \mathrm{Bi}+3 \mathrm{Se}=\mathrm{Bi}_{2} \mathrm{Se}_{3}, 2 \mathrm{Cu}+\mathrm{Se}=\mathrm{Cu}_{2} \mathrm{Se}\right)$ which emitted heat and drove the other two reactions $\left(\mathrm{Bi}_{2} \mathrm{Se}_{3}+2 \mathrm{Bi}_{2} \mathrm{O}_{3}=3 \mathrm{Bi}_{2} \mathrm{SeO}_{2}, 3 \mathrm{Bi}_{2} \mathrm{SeO}_{2}+3 \mathrm{Cu}_{2} \mathrm{Se}=6 \mathrm{BiCuSeO}\right)$. Through optimizing reaction parameters such as sample density and reaction atmosphere, etc. the $Z T$ value could be enhanced to 1.2 at $923 \mathrm{~K}$ for $\mathrm{Bi}_{0.94} \mathrm{~Pb}_{0.06} \mathrm{CuSeO}$ [43].

Although the mechanical alloying (MA) method was applied to BiCuSeO systems in 2013 [32], it was not widely used because of the uncontrollable $\mathrm{Bi}_{2} \mathrm{O}_{3}$ impurity. Compared with solid-state reaction, mechanical alloying is simple, less time-consuming, and much more convenient for large-scale productions. Taking into account these advantages, $\mathrm{Wu}$ et al. systematically investigated the mechanical alloying mechanism for $\mathrm{BiCuSeO}$ [33], instead of raw materials $\left(\mathrm{Bi}_{1} \mathrm{Bi}_{2} \mathrm{O}_{3}, \mathrm{Cu}\right.$, and $\left.\mathrm{Se}\right)$ powders used in the solid-state reaction, $\mathrm{Bi}, \mathrm{CuO}$, and Se were selected as starting powders to avoid the $\mathrm{Bi}_{2} \mathrm{O}_{3}$ second phase. Encouragingly, pure single phase $\mathrm{BiCuSeO}$ was obtained through ball milling at $500 \mathrm{rpm}$ for $7 \mathrm{~h}$. Apparently, the above results confirmed that mechanical alloying is an effective and promising method to synthesize BiCuSeO $[8,24]$.

\subsection{Attempting to Synthesize BiCuSeO Single Crystals}

In $\mathrm{BiCuSeO}$ systems, due to the layered structure, carrier scattering along the in-plane direction is much smaller than that along the out-plane direction. Therefore, we can expect a much higher carrier mobility in the single crystal than that of $22 \mathrm{~cm}^{2} \cdot \mathrm{V}^{-1} \cdot \mathrm{s}^{-1}$ obtained in polycrystalline BiCuSeO [11], hence a considerable $Z T$ value. To date, it is still a challenge to synthesize large size BiCuSeO single crystal. Dong et al. [44] made a significant step in BiCuSeO single crystal synthesis. They successfully synthesized BiCuSeO single crystals through a flux method at $963 \mathrm{~K}, 1003 \mathrm{~K}$ and $1048 \mathrm{~K}$, respectively. BiCuSeO crystals with a typical size of $2.5 \times 2 \times 0.05 \mathrm{~mm}^{3}$ were obtained [45]. Meanwhile, Wu et al. [46] 
synthesized $\mathrm{Bi}_{1-x} \mathrm{~Pb}_{x} \mathrm{CuSeO}$ film with high texture orientation through the pulsed laser deposition technique on the $\mathrm{SrTiO}_{3}$ (001) substrates, a high power factor of $\sim 1.2 \mathrm{~mW} \cdot \mathrm{m}^{-1} \cdot \mathrm{K}^{-2}$ at $673 \mathrm{~K}$ was realized. Therefore, a higher ZT can be expected in BiCuSeO single crystals. However, the challenge still lies in obtaining sufficiently large single crystals to investigate the thermal transport properties.

Apart from various attempts to enhance thermoelectric performance mentioned above, the interested readers are encouraged to refer to these extensive works that have been done on $\mathrm{BiCuSeO}$ systems, such as ultrathin $\mathrm{BiCuSeO}$ nanosheets [47], elastic and thermal properties [48,49], phonon transport [50,51], oxidation states [52], Cu vacancies [53,54], thermal stability [55,56], and the TEM study on BiCuSO and BiCuSeO that shows that $\mathrm{Cu}$ deficiency also plays a role in the stability and properties of those layered oxychalcogenides [54]. All of these studies largely enrich the understanding of $\mathrm{BiCuSeO}$ systems and have a great sense for future research.

\section{Exploring the Origins of Low Thermal Conductivity in BiCuSeO}

The large $\mathrm{ZT}$ value of $\mathrm{BiCuSeO}$ is derived from its low thermal conductivity $(\mathrm{\kappa})$ in temperatures ranging from $300 \mathrm{~K}\left(\sim 0.9 \mathrm{~W} \cdot \mathrm{m}^{-1} \cdot \mathrm{K}^{-1}\right)$ to $923 \mathrm{~K}\left(\sim 0.45 \mathrm{~W} \cdot \mathrm{m}^{-1} \cdot \mathrm{K}^{-1}\right)$ [6]. The low thermal conductivity of $\mathrm{BiCuSeO}$ system is supposed to originate from its strong crystal anharmonicity (larger Grüneisen parameter, $\gamma \sim 1.5$ ) [11], weak chemical bond (Young's modulus, E 78.8 GPa at $300 \mathrm{~K}$ ) [3], and low Debye temperature $\left(\Theta_{\mathrm{D}} \sim 243 \mathrm{~K}\right)$ [11]. Thus, any further detailed investigations on its thermal conductivity mechanism will help readers to clarify the low thermal transport behaviors. Here, we introduce several of the latest studies that may reveal the origins of low thermal conductivity for BiCuSeO.

\subsection{Low Thermal Conductivity Due to In-Layer/Interlayer Anharmonic Vibrations}

Ding et al. [57] systematically studied the vibration modes of BiCuSeO and proved that the anharmonic vibrations and structural scattering of phonons are partially caused by in-layer and interlayer off-phase vibration modes. Apart from this, the calculated Grüneisen parameters indicate that $\mathrm{Bi}$ is the source of strong crystal anharmonicity.

Figure 1 shows the thermal conductivity of BiCuSeO. Given a defect-free BiCuSeO crystal, both calculated values and experimental values are almost fitted at high temperatures. However, at low temperatures, the difference between two lines is very significant. To explain the origin of this difference, it is necessary to analyze the phonon spectrum and the power spectrum (PS) of velocity autocorrelation function (VAF) for BiCuSeO. Through analyzing the vibration modes of each branch and studying the atomic motions, an unexpected movement was found. The Cu-Se atom layer vibrates synchronously and the Bi-O atom layer vibrates with a different phase. This discovery directly indicates the existence of interlayer interaction.

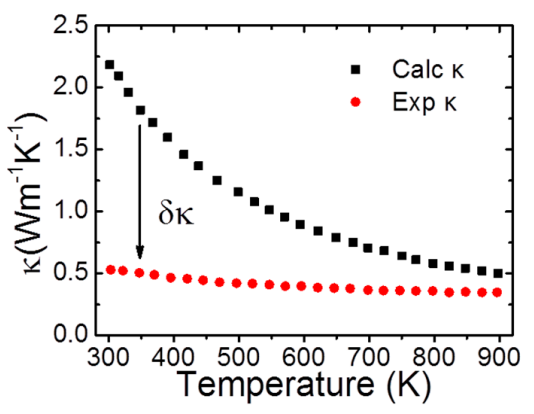

Figure 1. Calculated thermal conductivity. The black squares represent the calculated total thermal conductivity, and the red circles represent the experimental data. Reproduced with permission from Reference [57]. Copyright 2015, IOP Publishing.

Figure 2 shows the calculated power spectrum (PS) of the velocity autocorrelation function (VAF). From the PS, the frequencies of different atomic motions are determined. As shown in Figure $2 \mathrm{a}$, if the 
vibration frequencies of $\mathrm{Bi}$ and Se are synchronous, their peaks in the PS of self-VAF will appear at the same frequencies in the cross-VAF spectrum [57]. It is readily seen from the Figure 2a that the negative peaks in the PS of Bi/Se at 0.37 and 0.84 do not exist in the PS of Bi or Se. This means that the vibration frequencies between $\mathrm{Bi}$ and Se are different, and proves the existence of interlayer off-phase interaction by comparing with the above results. Similar to that shown in Figure 2a, negative peaks in the PS of $\mathrm{Cu} / \mathrm{Se}$ can be found at 0.47 and $0.75 \mathrm{THz}$ in Figure 2b, confirming the in-layer interaction between $\mathrm{Cu}$ and Se.

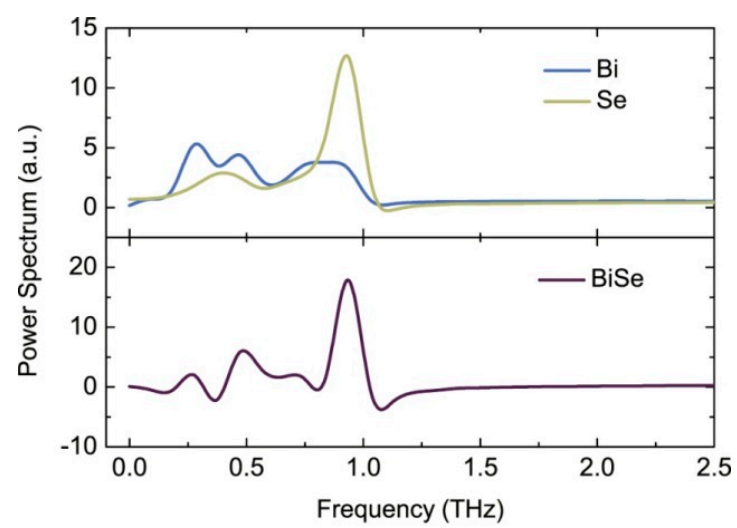

(a)

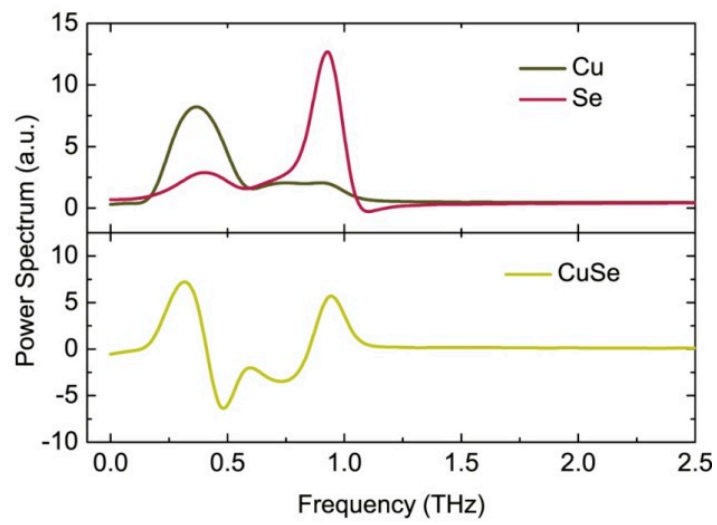

(b)

Figure 2. Power spectrum of the self-and cross-VAF. (a) Power spectrum of self- and cross-VAF of Bi and Se. Blue and beige lines represent $\mathrm{Bi}$ and Se self-VAF, respectively. The Bi/Se cross-VAF shows with purple line; (b) Power spectrum of self- and cross-VAF of $\mathrm{Cu}$ and Se. Brown and purple lines represent $\mathrm{Cu}$ and Se self-VAF, respectively. The $\mathrm{Cu} / \mathrm{Se}$ cross-VAF is represented yellow line. Reproduced with permission from Reference [46]. Copyright 2015, IOP Publishing.

The mode Grüneisen parameters were calculated by quasi-harmonic approximation. As shown in Figure 3, at low frequency $(<2.5 \mathrm{THz})$, due to the strong interaction between acoustic phonons and optical phonons, acoustic phonons can be significantly scattered by the phonon-phonon Umklapp processes. At middle frequency $(2.5-6 \mathrm{THz})$, the mode Grüneisen parameters from approximately 2 to 2.5 are contributed by the heavy element $\mathrm{Bi}$ around the $\mathrm{G}$ and $\mathrm{Z}$ points. Considering that the $\mathrm{O}$ is light and the $\mathrm{O}-\mathrm{O}$ bonds are mainly involved to the Grüneisen parameters below 1, the large mode Grüneisen parameters above $6 \mathrm{THz}$ are actually related to $\mathrm{Bi}-\mathrm{O}$ bonds. Thus, the viewpoint that large Grüneisen parameter of $\mathrm{BiCuSeO}$ almost entirely related to heavy $\mathrm{Bi}$ was confirmed by their calculations. Overall, the low thermal conductivity was confirmed to derive from the in-layer and interlayer off-phase vibration modes and heavy Bi. 


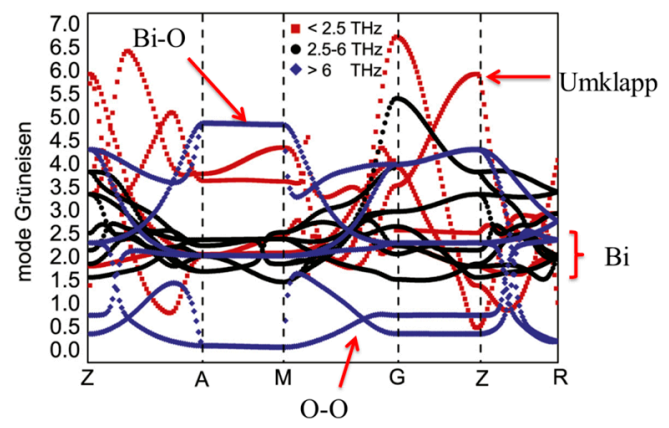

Figure 3. Mode Grüneisen parameters of BiCuSeO along the high symmetry path Z-A-M-G-Z-R-A. The mode Grüneisen parameters of acoustic branches are shown with red squares, black circles are related to the frequencies between 2.5 and $6 \mathrm{THz}$, and the phonon modes of $\mathrm{O}$ above $6 \mathrm{THz}$ are shown with blue diamonds. Reproduced with permission from Reference [46]. Copyright 2015 IOP Publishing.

\subsection{Heavy Bi Is a Predominant Factor That Causes Low Thermal Conductivity}

Saha [58] carried out the first-principles density functional theory (DFT) calculation to compare the lattice dynamics, phonon dispersion, and Mode Grüneisen dispersion between BiCuSeO and $\mathrm{LaCuSeO}$. It was found that the better thermal insulator of $\mathrm{BiCuSeO}$ than that of $\mathrm{LaCuSeO}$ is likely due to the mass difference between $\mathrm{Bi}$ and La. Figure 4 shows the calculated phonon dispersion and DOS of (a) BiCuSeO and (b) LaCuSeO along the high-symmetry lines of the Brillouin zone. For the low-frequency modes, because of the same structure and stable interatomic force (IF) constants, the mode frequency difference of $\mathrm{BiCuSeO}$ and $\mathrm{LaCuSeO}$ can be described by the mass difference. Figure $4 \mathrm{c}$ puts the calculated phonon dispersion of $\mathrm{BiCuSeO}$ and $\mathrm{LaCuSeO}$ into one picture for a direct comparison. In Figure 4d, it can be seen that the red solid lines and the blue dashed lines fit very well in the low-frequency acoustic region, which means the difference between $\mathrm{BiCuSeO}$ and $\mathrm{LaCuSeO}$ at low-frequency acoustic phonons mode is caused by atomic mass discrepancies between Bi and La.
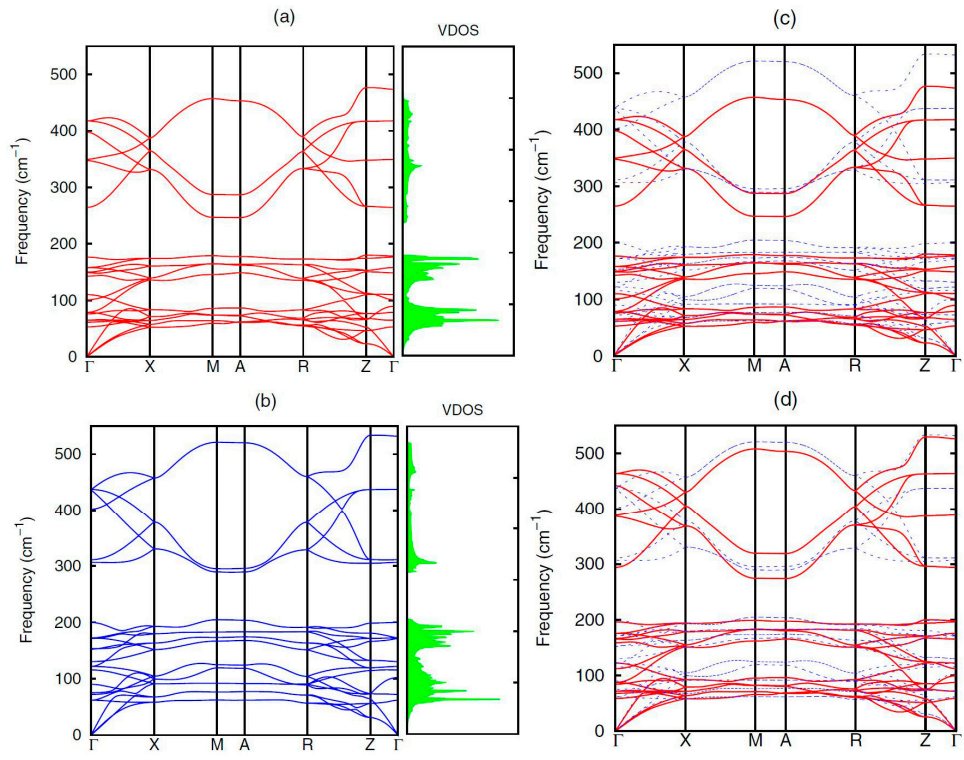

Figure 4. Red line and blue line in $(\mathbf{a}, \mathbf{b})$ represent the calculated phonon dispersion of $\mathrm{BiCuSeO}$ and LaCuSeO along the high-symmetry lines of the Brillouin zone; (c) Calculated phonon dispersion curves of $\mathrm{BiCuSeO}$ (red) and $\mathrm{LaCuSeO}$ (blue) for a direct comparison; (d) Red solid lines represent the normalized phonon dispersion data of $\mathrm{BiCuSeO}(\mathbf{a})$, while the blue dashed lines represent the calculated original phonon dispersion data of LaCuSeO. Reproduced with permission from Reference [47]. Copyright 2015, The American Physical Society. 
Figure 5a shows the atomic displacement patterns for the lowest-frequency optical (LFO) mode of BiCuSeO (Eu (IR,TO1) $\sim 53 \mathrm{~cm}^{-1}$ ) and $\mathrm{LaCuSeO}\left(E g(\mathrm{R}, 1) \sim 62 \mathrm{~cm}^{-1}\right)$. The larger displacement in heavy $\mathrm{Bi}$ atoms is observed, which leads to higher anharmonic effects. Figure $5 \mathrm{~b}$ shows the mode Grüneisen dispersion of above lowest-frequency optical (LFO), longitudinal acoustic (LA), and transverse acoustic (TA) modes in BiCuSeO and LaCuSeO. Because LFO mode $E u$ (IR,TO1) in BiCuSeO behaves as a quasi-acoustic mode [58], the acoustic modes can be hybridized more strongly in $\mathrm{BiCuSeO}$ than in $\mathrm{LaCuSeO}$. It can lead to an extensive acoustic-optical phonon scattering and then low thermal conductivity. Overall, the same structure as they are, heavy Bi outperforms La in reducing the thermal conductivity $(\mathrm{K})$. It illustrates the contribution of the heavy Bi element to the low thermal conductivity in BiCuSeO. In 2016, Saha et al. [48] used first-principle calculations to continuously explore the origins of low thermal conductivity of BiCuSeO. Compared with $\mathrm{LaCuSeO}$, they found that $\mathrm{BiCuSeO}$ has a lower shear modulus, lower Young's modulus, lower acoustic velocity, lower Debye temperature, and larger Grüneisen parameter.
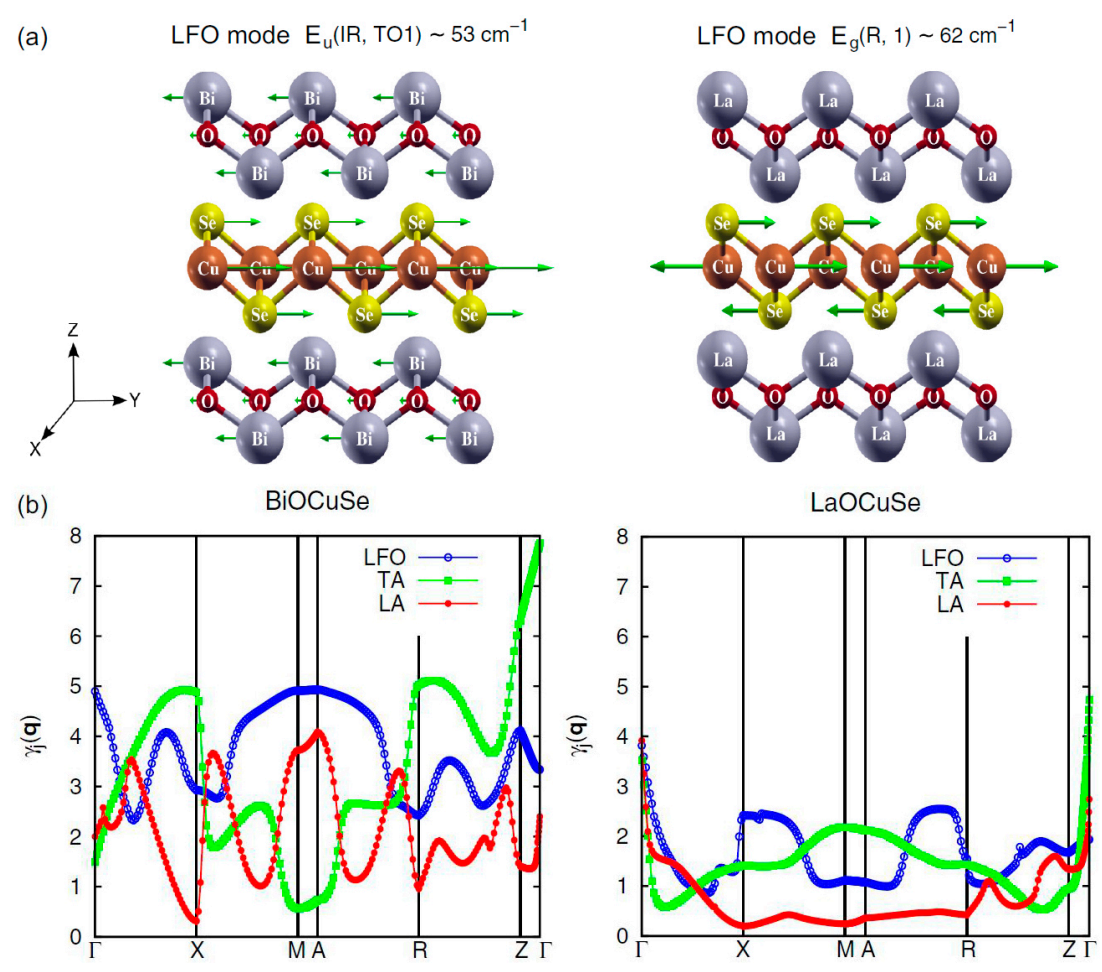

Figure 5. (a) Atomic displacement patterns $E u$ (IR,TO1) $\sim 53 \mathrm{~cm}^{-1}$ and $E g(\mathrm{R}, 1) \sim 62 \mathrm{~cm}^{-1}$ for the respective lowest-frequency optical (LFO) mode in $\mathrm{BiCuSeO}$ (left) and in $\mathrm{LaCuSeO}$ (right), arrows represent the atomic movement directions; (b) Mode Grüneisen dispersion of the above LFO mode (blue) in comparison to that of the longitudinal acoustic (red) and transverse acoustic (green) movement in $\mathrm{BiCuSeO}$ (left) and in $\mathrm{LaCuSeO}$ (right), respectively. Reproduced with permission from Reference [47]. Copyright 2015, The American Physical Society.

\subsection{Dose Cu Matter in Low Thermal Conductivity?}

Vaqueiro et al. [59] believe the origins of low thermal conductivity of BiCuSeO mostly comes from $\mathrm{Cu}$ atoms and partly from $\mathrm{Bi}$ atoms. Through first principle calculation and in-situ neutron diffraction experiments, a low-energy vibrational mode of $\mathrm{Cu}$ in $\mathrm{BiCuSeO}$ was unveiled. Powder neutron diffraction data on $\mathrm{BiCuMO}(\mathrm{M}=\mathrm{S}$, $\mathrm{Se}, \mathrm{Te})$ revealed the atomic displacement parameter (ADP) among the atoms. As shown in Figure 6, in all the three samples (BiCuMO, M = S, Se, Te), the ADP for $\mathrm{Cu}$ is persistently larger than those for other elements in the whole temperature range. It illustrates that $\mathrm{Cu}$ possesses a stronger local mobility. 


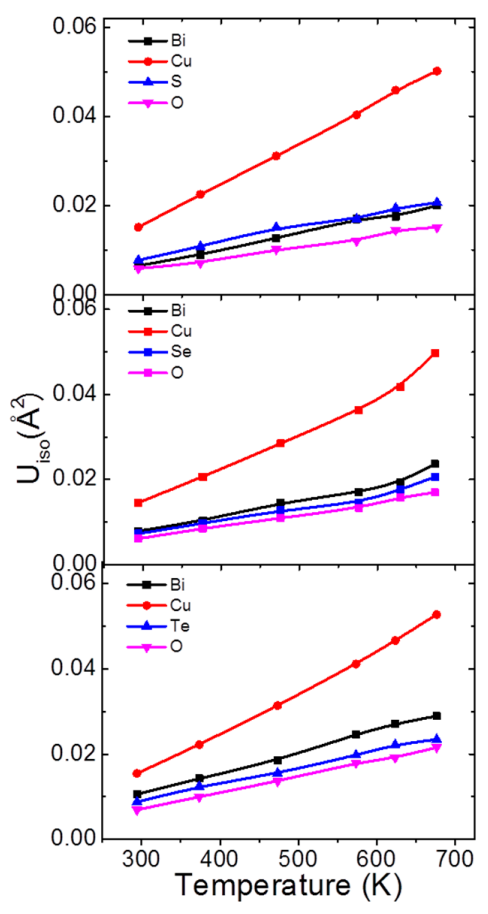

Figure 6. ADPs for BiCuMO (M = S, Se, Te) as a function of temperature. Reproduced with permission from Reference [48]. Copyright 2015, The American Royal Society of Chemitry.

Phonon vibrations for $\mathrm{BiCuSeO}$ were also calculated in order to explore the origins of the low thermal conductivity. As shown in Figure 7, the total vibrational DOS of BiCuSeO is projected on each element. At low frequency, the VDOS of $\mathrm{Cu}$ is much higher than that of $\mathrm{Bi}$, which indicates that the $\mathrm{Cu}$ has a greater effect on total vibration than $\mathrm{Bi}$ for $\mathrm{BiCuSeO}$. Meanwhile, through calculating the mode-resolved Grüneisen parameter projected onto the atoms, $\mathrm{Cu}$ and chalcogen atoms were found to contribute more to the large total Grüneisen parameter. The obtained conclusions are determined by the following three comparisons: (1) The $\mathrm{Cu}-\mathrm{Se}$ bond distance (2.5143 $\AA$ [59]) in $\mathrm{BiCuSeO}$ is longer than that in $\mathrm{CuGaSe}_{2}$ (2.385 $\AA$ [60]) in the case of the same tetrahedral coordination for $\mathrm{Cu}$; (2) The Einstein temperature $\Theta_{\mathrm{E}}$ for $\mathrm{Cu}$ and for the rattler atom of skutterudite, $\mathrm{LaFe}_{4} \mathrm{Sb}_{12}$ [61] is comparable; (3) The $\mathrm{Cu}-\mathrm{Se}$ bond is soft and there is no suitable path for $\mathrm{Cu}$ mobility in layered structure. The $\mathrm{Cu}$ rattling mode [59] in BiCuSeO derived from the weak $\mathrm{Cu}-\mathrm{Se}$ bonding was put forward. In summary, it can be seen that the presence of a localized low-energy vibrational mode on the $\mathrm{Cu}$ [59] contributes a great deal to the low thermal conductivity of BiCuSeO.

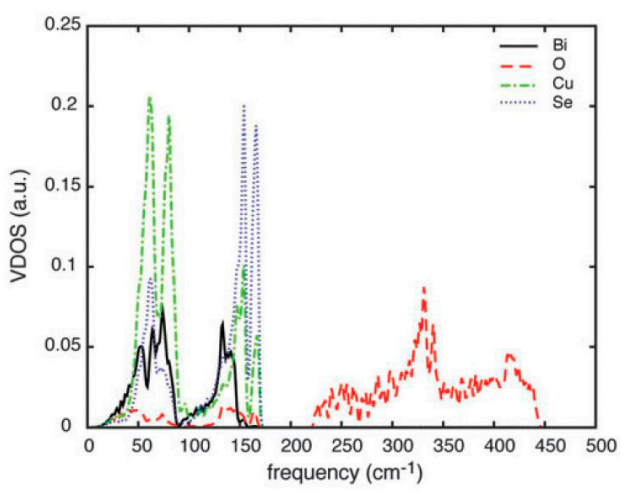

Figure 7. Total vibrational DOS of $\mathrm{BiCuSeO}$ projected on each element ( $\mathrm{Bi}, \mathrm{Cu}, \mathrm{Se}, \mathrm{O})$. Reproduced with permission from Reference [48]. Copyright 2015, The American Royal Society of Chemitry. 
Generally, the contribution of high-frequency optical phonons to total lattice thermal conductivity is so small that it can be ignored. However, in the BiCuSeO system, Shao et al. [51] found that high-frequency (above $213 \mathrm{~cm}^{-1}$ ) optical phonons contributed more than one-third to the lattice thermal conductivity through first-principles calculations. Kumar et al. obtained a similar result that optical phonons can dramatically reduce lattice thermal conductivity $\kappa_{\text {lat }}$ by a first principle phonon analysis [62]. Both reports pointed out that the contribution of optical phonons is considerable and should not be ignored, the results provide a promising route for further clarifying the origins of low thermal conductivity of BiCuSeO.

\subsection{Microstructures Investigations on Heavy Ba-Doped BiCuSeO}

Extensive experiments confirmed that alkaline-earth metals doping is effective to enhance the thermoelectric performance of $\mathrm{Bi}_{1-x} \mathrm{M}_{x} \mathrm{CuSeO}(\mathrm{M}=\mathrm{Mg}, \mathrm{Ca}, \mathrm{Sr}, \mathrm{Ba})[1,2,4,6,30,63,64]$, among them the high-performance doped $\mathrm{BiCuSeO}$ systems exhibit the extremely low thermal conductivity. However, trying to explain origins of low thermal conductivity via investigating on the microstructures of these alkaline-earth-metal doped $\mathrm{BiCuSeO}$ remain largely unexplored. Feng et al. investigated the microstructures of $\mathrm{Bi}_{0.875} \mathrm{Ba}_{0.125} \mathrm{CuSeO}$ using scanning transmission electron microscopy (STEM) [65], and found a ubiquitous nano-scale $\mathrm{BaSeO}_{3}$ second phase in $\mathrm{BiCuSeO}$ matrix which played a positive role for further reduction of the thermal conductivity. The solubility limit of $\mathrm{Ba}$ in BiCuSeO was found to be less than 5\% [65]. However, the highest $Z T$ value was obtained in $\mathrm{Bi}_{0.875} \mathrm{Ba}_{0.125} \mathrm{CuSeO}$, where as high as $12.5 \%$ Ba was dissolved in the matrix. The visual observation of the second phase $\mathrm{BaSeO}_{3}$ through STEM was a reasonable explanation of low thermal conductivity. As shown in Figure $8 \mathrm{c}$, the dark precipitates are $\mathrm{BaSeO}_{3}$ which widely exist in the $\mathrm{Bi}_{0.875} \mathrm{Ba}_{0.125} \mathrm{CuSeO}$, but there are no precipitates in $\mathrm{Bi}_{0.95} \mathrm{Ba}_{0.05} \mathrm{CuSeO}$.

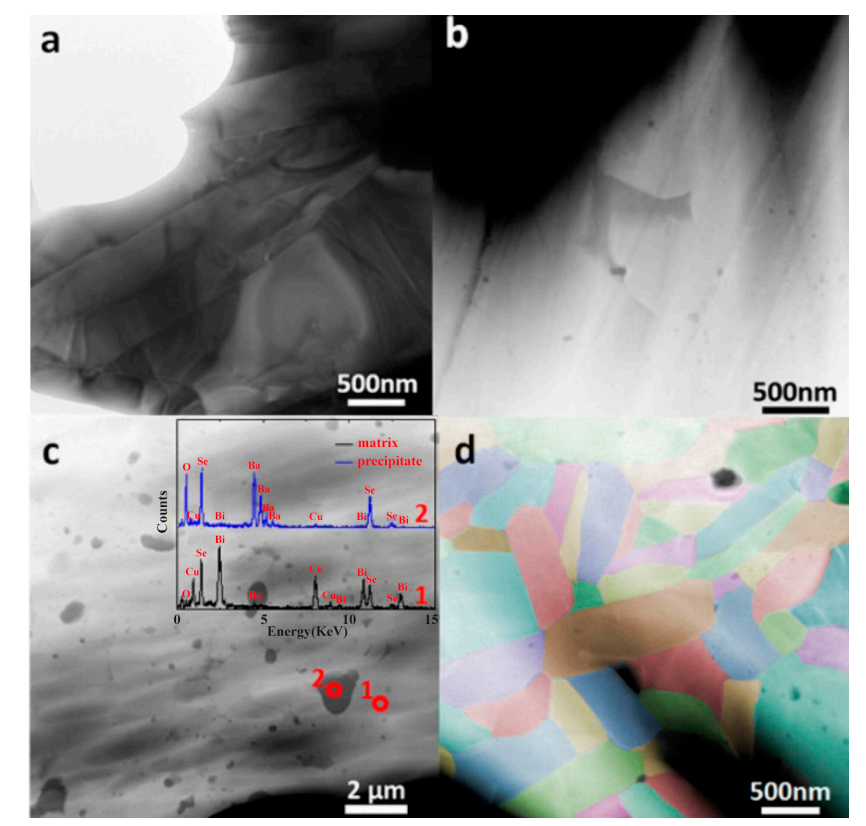

Figure 8. Low-magnification micrographs of (a) BiCuSeO in TEM mode; (b) $\mathrm{Bi}_{0.95} \mathrm{Ba}_{0.05} \mathrm{CuSeO}$ in STEM mode and (c) $\mathrm{Bi}_{0.875} \mathrm{Ba}_{0.125} \mathrm{CuSeO}$ in STEM mode; (d) Grains of $\mathrm{Bi}_{0.875} \mathrm{Ba}_{0.125} \mathrm{CuSeO}$. Reproduced with permission from Reference [65]. Copyright 2016, Elsevier Science.

Benefitting from the all-scale phonons scattering from the interface of the layered structure, the Ba-Bi point defects and the $\mathrm{BaSeO}_{3}$ second phase, the lattice thermal conductivity of $\mathrm{Bi}_{0.875} \mathrm{Ba}_{0.125} \mathrm{CuSeO}$ is lower than that of pristine $\mathrm{BiCuSeO}$ and $\mathrm{Bi}_{0.95} \mathrm{Ba}_{0.05} \mathrm{CuSeO}$ in the entire temperature range, as shown in Figure 9. 


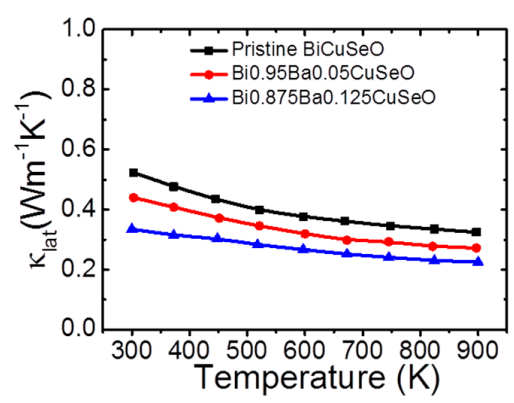

Figure 9. The lattice thermal conductivity of $\mathrm{Bi}_{1-x} \mathrm{Ba}_{x} \mathrm{CuSeO}(x=0,0.05,0.125)$. Reproduced with permission from Reference [65]. Copyright 2016, Elsevier Science.

\section{Typical Examples to Enhance Thermoelectric Performance of BiCuSeO}

\subsection{Enhancing Electrical Conductivity by Modulation Doping}

The electrical conductivity is determined by carrier concentration (n) and carrier mobility $(\mu)$. On the one hand, heavy doping can improve the carrier concentration significantly. On the other hand, the excessive dopants decrease the carrier mobility obviously because of the intensive ionized impurity scattering [66]. Therefore, the methods that enlarge the carrier mobility and maintain the carrier concentration can be expected to enhance the electrical transport properties. Pei et al. [8] proposed the utilization of 3D modulation doping in the synthesis of BiCuSeO. Even though modulation doping indeed works in a 2D material, however, further clarification is needed to confirm it exists in a 3D system. Figure 10a presents the pristine $\mathrm{BiCuSeO}$ which possesses relatively high carrier mobility $\left(\sim 22 \mathrm{~cm}^{2} \cdot \mathrm{V}^{-1} \cdot \mathrm{s}^{-1}\right)$ and low carrier concentration $\left(\sim 1.1 \times 10^{18} \mathrm{~cm}^{-3}\right)$ [11]. In contrast, Figure 10c presents the uniformly heavy Ba-doped $\mathrm{Bi}_{0.875} \mathrm{Ba}_{0.125} \mathrm{CuSeO}$ with high carrier concentration $\left(\sim 1.2 \times 10^{21} \mathrm{~cm}^{-3}\right)$ and low carrier mobility $\left(\sim 2.1 \mathrm{~cm}^{2} \cdot \mathrm{V}^{-1}\right)$ [2] due to large ionized impurity scattering. Figure $10 \mathrm{~b}$ presents the proposed mechanism of 3D modulation doping which is actually a two-phase composite with undoped $\mathrm{BiCuSeO}$ and heavy-doped $\mathrm{Bi}_{0.875} \mathrm{Ba}_{0.125} \mathrm{CuSeO}$ each accounting for 50 percent. Meanwhile, the Fermi level of modulation doping is higher than that of uniformly doping and lower than that of the undoped sample. There is a proceeding that holes flow from doped phase to undoped phase due to the successively small difference of chemical potential. Thus, the heavy doped phase sustains the high carrier concentration while the undoped phase provides a path that is easy to conduct, and both of these are responsible for the high electrical conductivity.

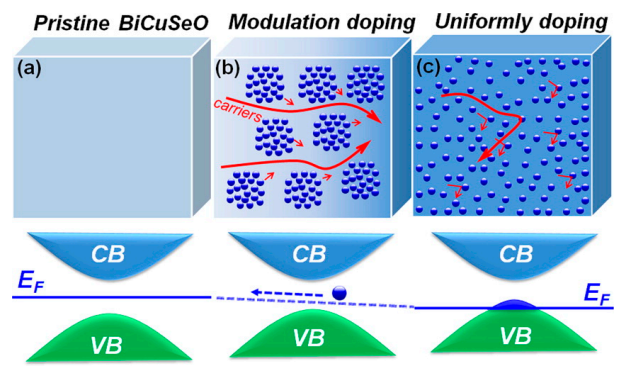

Figure 10. Three-dimensional schematic showing the band structures and Fermi energy levels for (a) the pristine $\mathrm{BiCuSeO}$; (b) modulation doped $\mathrm{Bi}_{0.875} \mathrm{Ba}_{0.125} \mathrm{CuSeO}(50 \% \mathrm{BiCuSeO}+50 \%$ $\mathrm{Bi}_{0.75} \mathrm{Ba}_{0.25} \mathrm{CuSeO}$ ); and (c) uniformly doped $\mathrm{Bi}_{0.875} \mathrm{Ba}_{0.125} \mathrm{CuSeO}$. Reproduced (adapted) with permission from Reference [8]. Copyright 2014, American Chemical Society.

Figure 11 shows the thermoelectric properties of modulation doped $\mathrm{Bi}_{0.875} \mathrm{Ba}_{0.125} \mathrm{CuSeO}$, undoped BiCuSeO, uniformly doped $\mathrm{Bi}_{0.875} \mathrm{Ba}_{0.125} \mathrm{CuSeO}$ and heavily doped $\mathrm{Bi}_{0.75} \mathrm{Ba}_{0.25} \mathrm{CuSeO}$. Benefited from the high electrical concentration and mobility, the electrical conductivity of modulation 
doped $\mathrm{Bi}_{0.875} \mathrm{Ba}_{0.125} \mathrm{CuSeO}$ is higher than that of both undoped $\mathrm{BiCuSeO}$ and uniformly doped $\mathrm{Bi}_{0.875} \mathrm{Ba}_{0.125} \mathrm{CuSeO}$ at $300-923 \mathrm{~K}$, as shown in Figure 11a. Besides, due to the relatively high Seebeck coefficient, the power factor of the modulation doped sample is much higher than the other three samples and reaches approximately $10 \mu \mathrm{W} \cdot \mathrm{cm}^{-1} \cdot \mathrm{K}^{-2}$ at $923 \mathrm{~K}$, as shown in Figure $11 \mathrm{~b}$,c. Due to the high power factor and relatively low thermal conductivity (Figure 11d), the ZT value (Figure 11f) of the modulation doped sample has a great improvement, and the highest $Z T \sim 1.4$ is achieved at $923 \mathrm{~K}$. These results indicate that the 3D modulation doping provides an effective method to improve the thermoelectric performance and affords an alternative reference for other thermoelectric systems.
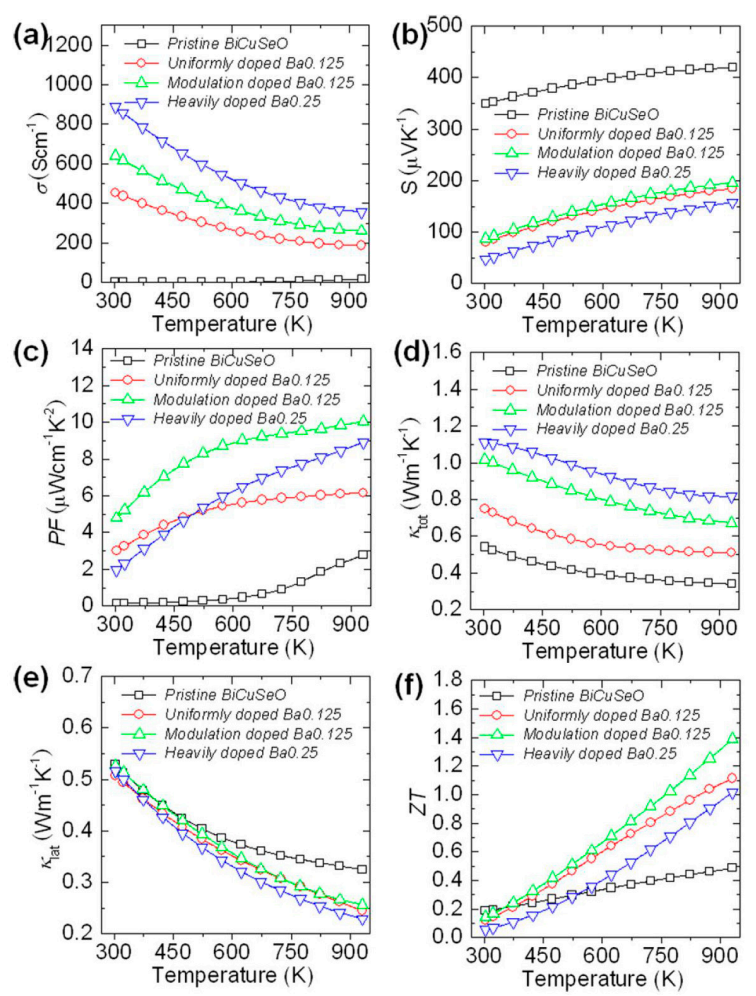

Figure 11. Thermoelectric properties of pristine $\mathrm{BiCuSeO}$, uniformly doped $\mathrm{Bi}_{0.875} \mathrm{Ba}_{0.125} \mathrm{CuSeO}$, modulation doping, and heavily $\mathrm{Ba}$ doped $\mathrm{Bi}_{0.75} \mathrm{Ba}_{0.25} \mathrm{CuSeO}$. (a) The electrical conductivity; (b) the Seebeck coefficient; (c) the power factor; (d) total thermal conductivity; (e) lattice thermal conductivity; and (f) the figure of merit ZT. Reproduced (adapted) with permission from Reference [8]. Copyright 2014, American Chemical Society.

\subsection{Improving ZT Value of BiCuSeO by Synergetic Approaches}

\subsection{1. $\mathrm{Pb} / \mathrm{Ca}$ Dual-Doping}

Lan et al. reported the electrical conductivity could be obviously enhanced through $\mathrm{Pb}$ doping at the Bi site. Besides, the Seebeck coefficient remains at a high level due to the increased effective mass. Both the higher electrical conductivity and comparable Seebeck coefficient lead to a larger power factor of $\mathrm{Pb}$ than that of other dopants [43]. Meanwhile, the $\mathrm{Ca}$ doping could reduce the lattice thermal conductivity effectively because of the large mass difference between $\mathrm{Bi}$ and $\mathrm{Ca}$ [6]. Therefore, $\mathrm{Pb} / \mathrm{Ca}$ dual-doping simultaneously realized enhancing power factor and reducing thermal conductivity.

Liu et al. [10] introduced an all-scale structural optimization strategy, which is realized by dual-doped $\mathrm{Ca}$ and $\mathrm{Pb}$ at the $\mathrm{Bi}$ site to effectively enhance electrical conductivity and maintain Seebeck coefficient. Additionally, the dual-doping simultaneously optimized the microstructures at the atomic scale, nanoscale, and mesoscale, which could effectively reduce thermal conductivity. For the atomic scale, substitutions of $\mathrm{Bi}$ with $\mathrm{Pb}$ increased the carrier concentration and introduced 
point defects. For nanoscale and mesoscale, $\mathrm{CaO}_{2}$ nanoclusters and Bi-rich quantum dots besides the grain boundaries offset the increase of electrical conductivity originating from the increased carrier concentration. The novel dual-doping combined the advantages of these two dopants and achieved extremely good outcome as expected.

Figure 12 shows the effects of $\mathrm{Pb} / \mathrm{Ca}$ dual-doping through comparing the best dual-doped $\mathrm{Bi}_{0.88} \mathrm{Ca}_{0.06} \mathrm{~Pb}_{0.06} \mathrm{CuSeO}$ [10] with single doping $\mathrm{Bi}_{0.925} \mathrm{Ca}_{0.75} \mathrm{CuSeO}$ [6] and $\mathrm{Bi}_{0.94} \mathrm{~Pb}_{0.06} \mathrm{CuSeO}$ [43] in TE properties. As shown in Figure 12a, the electrical conductivity of dual-doped $\mathrm{Bi}_{0.88} \mathrm{Ca}_{0.06} \mathrm{~Pb}_{0.06} \mathrm{CuSeO}$ is much higher than that of $\mathrm{Bi}_{0.925} \mathrm{Ca}_{0.075} \mathrm{CuSeO}$ while slightly higher than that of $\mathrm{Bi}_{0.94} \mathrm{~Pb}_{0.06} \mathrm{CuSeO}$, which indicated in the positive role of $\mathrm{Pb}$ in regulating the electrical conductivity in the dual-doping. Meanwhile, due to a slightly difference in Seebeck coefficient (Figure 12b), the power factor (Figure 12c) of $\mathrm{Bi}_{0.88} \mathrm{Ca}_{0.06} \mathrm{~Pb}_{0.06} \mathrm{CuSeO}$ is larger than that of $\mathrm{Bi}_{0.925} \mathrm{Ca}_{0.075} \mathrm{CuSeO}$ in all temperature ranges. The power factor of $\mathrm{Bi}_{0.88} \mathrm{Ca}_{0.06} \mathrm{~Pb}_{0.06} \mathrm{CuSeO}$ below $700 \mathrm{~K}$ is comparable to $\mathrm{Bi}_{0.94} \mathrm{~Pb}_{0.06} \mathrm{CuSeO}$. While in a higher temperature range, the power factor of $\mathrm{Bi}_{0.88} \mathrm{Ca}_{0.06} \mathrm{~Pb}_{0.06} \mathrm{CuSeO}$ is larger because of its higher Seebeck coefficient (Figure 12b). In addition, both the lattice thermal conductivity and the total thermal conductivity of $\mathrm{Bi}_{0.88} \mathrm{Ca}_{0.06} \mathrm{~Pb}_{0.06} \mathrm{CuSeO}$ above $500 \mathrm{~K}$ are slightly lower than those of $\mathrm{Bi}_{0.94} \mathrm{~Pb}_{0.06} \mathrm{CuSeO}$ (Figure 12d,e), which could be attributed to the all scale structural phonon scattering. Overall, the $Z T$ value of dual-doped $\mathrm{Bi}_{0.88} \mathrm{Ca}_{0.06} \mathrm{~Pb}_{0.06} \mathrm{CuSeO}$ reached a record high 1.5 at $873 \mathrm{~K}$ (Figure 12f).
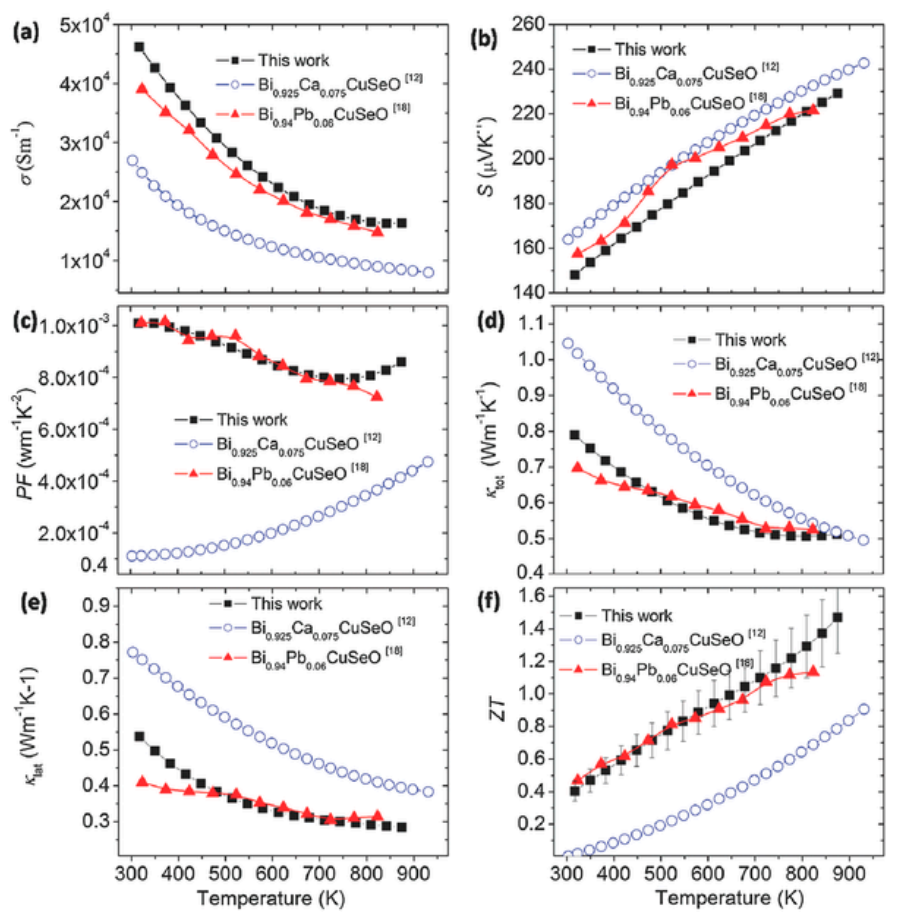

Figure 12. Thermoelectric properties of $\mathrm{Pb}$ and $\mathrm{Ca}$ dual-doping, $\mathrm{Ca}$ single doped $\left(\mathrm{Bi}_{0.925} \mathrm{Ca} \mathrm{a}_{0.075} \mathrm{CuSeO}\right)$ and $\mathrm{Pb}\left(\mathrm{Bi}_{0.94} \mathrm{~Pb}_{0.06} \mathrm{CuSeO}\right)$ single doped samples (a) the electrical conductivity; (b) the Seebeck coefficient; (c) the power factor; (d) total thermal conductivity; (e) lattice thermal conductivity; and (f) the figure of merit ZT. Reproduced with permission from Reference [10]. Copyright 2016, Wiley.

\subsubsection{Bi/Cu Dual Vacancies}

Li et al. [9] confirmed the existence of the inter-layer charge transmission mechanism between $\mathrm{Bi}$ vacancies and $\mathrm{Cu}$ vacancies through positron annihilation spectrometry (PAS). Served as the phonons scattering centers, vacancies in the lattice can reduce the thermal conductivity efficiently. However, vacancies also adversely affect the electrical conductivity due to the reception of electrons or holes. The introduction of the dual vacancies can reduce the thermal conductivity and improve 
the electrical conductivity at the same time. The reason is that when $\mathrm{Cu}$ vacancies and $\mathrm{Bi}$ vacancies are presented simultaneously, holes around the Bi vacancies' centers will be transferred to the $\mathrm{Cu}$ vacancies' centers. Because of the $\left(\mathrm{Cu}_{2} \mathrm{Se}_{2}\right)^{2-}$ layers where $\mathrm{Cu}$ vacancies located being responsible for the carrier transmission in $\mathrm{BiCuSeO}$, the increasing hole concentration can effectively enhance the electrical conductivity. Theoretically, the negatively charged centers of positive vacancies can annihilate positrons. As shown in Figure 13 b,c, the positrons are mostly trapped at the Bi vacancies and $\mathrm{Cu}$ vacancies in $\mathrm{Bi}_{0.975} \mathrm{CuSeO}$ and $\mathrm{BiCu}_{0.975} \mathrm{SeO}$, respectively, while positrons are mostly distributed around $\mathrm{Bi}$ vacancies in $\mathrm{Bi} / \mathrm{Cu}$ dual vacancy $\mathrm{BiCuSeO}$ (Figure 13d).

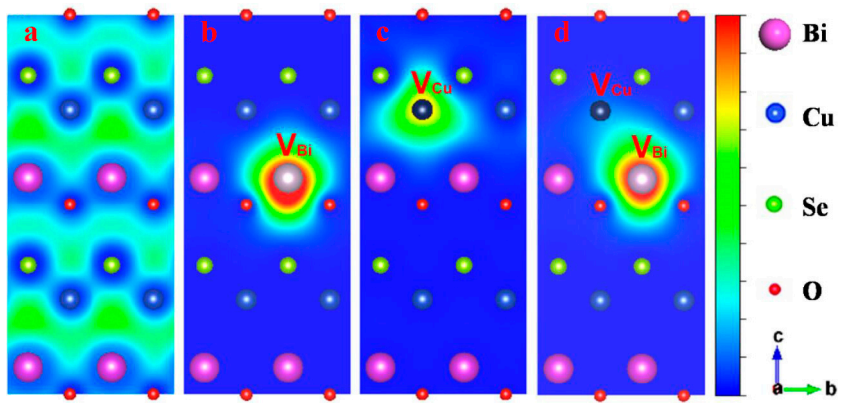

Figure 13. The projection of the positron density distribution for the (100) plane of (a) pure; (b) Bi vacancy; (c) Cu vacancy; and (d) Bi/Cu dual vacancies $\mathrm{BiCuSeO}$ samples. Reprinted (adapted) with permission from Reference [9]. Copyright 2015, American Chemical Society.

The projection of the positron density distribution proves the existence of carrier transmission from $\mathrm{Bi}$ vacancies to $\mathrm{Cu}$ vacancies in $\mathrm{Bi} / \mathrm{Cu}$ dual vacancies $\mathrm{BiCuSeO}$. It is easy to understand why the electrical conductivity of the dual vacancy sample is larger than that of monovacancy samples (Figure 14a). In addition, benefiting from the strong vacancy scattering in the whole temperature range (Figure 14e), the total thermal conductivity of dual vacancies sample is lower (Figure 14c) than that of monovacancy samples (Figure $14 \mathrm{~d}$ ). Hence, the $Z T$ value of dual vacancy $\mathrm{Bi}_{0.975} \mathrm{Cu}_{0.975} \mathrm{SeO}$ is higher than those of monovacancy $\mathrm{Bi}_{0.975} \mathrm{CuSeO}$ and $\mathrm{BiCu}_{0.975} \mathrm{SeO}$ in the whole temperature range, resulting in a relatively high $Z T$ of 0.84 was reached at $750 \mathrm{~K}$ for the dual vacancy sample (Figure 14f).
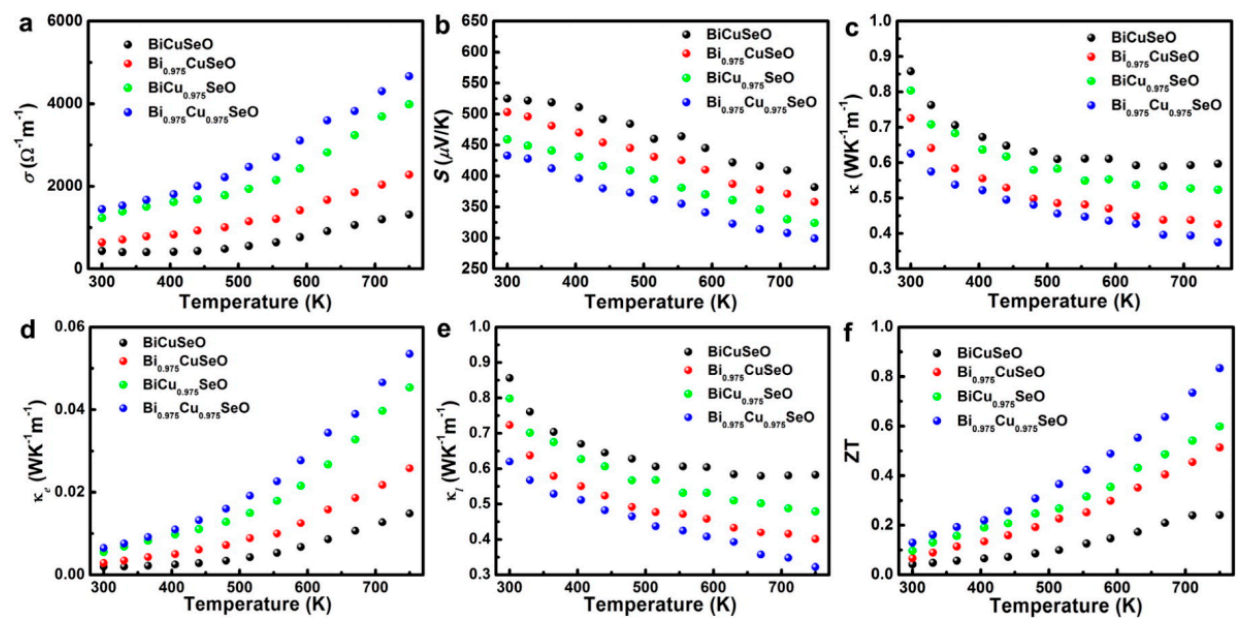

Figure 14. Thermoelectric properties of $\mathrm{Bi}_{1-x} \mathrm{Cu}_{1-y} \mathrm{SeO}$ samples, pristine $\mathrm{BiCuSeO}$ (black), $\mathrm{Bi}_{0.975} \mathrm{CuSeO}$ (red), $\mathrm{BiCu}_{0.975} \mathrm{SeO}$ (green), $\mathrm{Bi}_{0.975} \mathrm{Cu}_{0.975} \mathrm{SeO}$ (blue). (a) The electrical conductivity; (b) the Seebeck coefficient; (c) the total thermal conductivity; (d) electrical thermal conductivity; (e) lattice thermal conductivity; and (f) the figure of merit ZT. Reprinted (adapted) with permission from Reference [9]. Copyright 2015, American Chemical Society. 


\section{Summery and Perspective}

In this review, we introduced the latest achievements and progress in $\mathrm{BiCuSeO}$ system, including enhancing thermoelectric properties through doping and compositing, developing less time-consuming methods, attempting to synthesize single crystals, exploring the origins of low thermal conductivity, and typical examples to enhance thermoelectric performance of $\mathrm{BiCuSeO}$ systems. Aside from the progress mentioned above, there is still room left for further focusing, such as the synthesis of $\mathrm{BiCuSeO}$ single crystal and a high performance $n$-type $\mathrm{BiCuSeO}$, all of these are eagerly expected in the BiCuSeO system.

Acknowledgments: This work was supported by NSFC under Grant No. 51571007, the "Zhuoyue" program of Beihang University, the Recruitment Program for Young Professionals, and the Fundamental Research Funds for the Central Universities. We thank Professors Nita Dragoe, Ce-Wen Nan, Jing-Feng Li, David Berardan, Jiaqing He, Yuanhua Lin, Boping Zhang, Wei Cai, Jiehe Sui, Yanling Pei, Emilie. Amzallag, Celine Barreteau, Fu Li, Yong Liu, Wei Xu, Lin Pan, and Jing Li for plentiful discussions and fruitful collaborations on BiCuSeO systems.

Author Contributions: All the authors co-edited and wrote the paper.

Conflicts of Interest: The authors declare no conflict of interest.

\section{References}

1. Zhao, L.-D.; Berardan, D.; Pei, Y.L.; Byl, C.; Pinsard-Gaudart, L.; Dragoe, N. Bi ${ }_{1-x} \mathrm{Sr}_{x} \mathrm{CuSeO}$ oxyselenides as promising thermoelectric materials. Appl. Phys. Lett. 2010, 97, 092118. [CrossRef]

2. Li, J.; Sui, J.; Pei, Y.; Barreteau, C.; Berardan, D.; Dragoe, N.; Cai, W.; He, J.; Zhao, L.-D. A high thermoelectric figure of merit ZT > 1 in Ba heavily doped BiCuSeO oxyselenides. Energy Environ. Sci. 2012, 5, 8543-8547. [CrossRef]

3. Li, F.; Li, J.-F.; Zhao, L.-D.; Xiang, K.; Liu, Y.; Zhang, B.-P.; Lin, Y.-H.; Nan, C.-W.; Zhu, H.-M. Polycrystalline BiCuSeO oxide as a potential thermoelectric material. Energy Environ. Sci. 2012, 5, 7188-7195.

4. Li, F.; Wei, T.-R.; Kang, F.; Li, J.-F. Enhanced thermoelectric performance of Ca-doped BiCuSeO in a wide temperature range. J. Mater. Chem. A 2013, 1, 11942-11949. [CrossRef]

5. Pan, L.; Berardan, D.; Zhao, L.-D.; Barreteau, C.; Dragoe, N. Influence of Pb doping on the electrical transport properties of BiCuSeO. Appl. Phys. Lett. 2013, 102, 023902. [CrossRef]

6. Pei, Y.-L.; He, J.; Li, J.-F.; Li, F.; Liu, Q.; Pan, W.; Barreteau, C.; Berardan, D.; Dragoe, N.; Zhao, L.-D. High thermoelectric performance of oxyselenides: Intrinsically low thermal conductivity of Ca-doped BiCuSeO. NPG Asia Mater. 2013, 5, e47. [CrossRef]

7. Sui, J.H.; Li, J.; He, J.Q.; Pei, Y.L.; Berardan, D.; Wu, H.J.; Dragoe, N.; Cai, W.; Zhao, L.-D. Texturation boosts the thermoelectric performance of BiCuSeO oxyselenides. Energy Environ. Sci. 2013, 6, 2916-2920. [CrossRef]

8. Pei, Y.L.; Wu, H.; Wu, D.; Zheng, F.; He, J. High thermoelectric performance realized in a BiCuSeO system by improving carrier mobility through 3D modulation doping. J. Am. Chem. Soc. 2014, 136, 13902-13908. [CrossRef] [PubMed]

9. Li, Z.; Xiao, C.; Fan, S.J.; Deng, Y.; Zhang, W.S.; Ye, B.J.; Xie, Y. Dual vacancies: An effective strategy realizing synergistic optimization of thermoelectric property in BiCuSeO. J. Am. Chem. Soc. 2015, 137, 6587-6593. [CrossRef] [PubMed]

10. Liu, Y.; Zhao, L.-D.; Zhu, Y.; Liu, Y.; Li, F.; Yu, M.; Liu, D.-B.; Xu, W.; Lin, Y.-H.; Nan, C.-W. Synergistically optimizing electrical and thermal transport properties of $\mathrm{BiCuSeO}$ via a dual-doping approach. Adv. Energy Mater. 2016, 6, 1502423. [CrossRef]

11. Zhao, L.-D.; He, J.; Berardan, D.; Lin, Y.; Li, J.-F.; Nan, C.-W.; Dragoe, N. BiCuSeO oxyselenides: New promising thermoelectric materials. Energy Environ. Sci. 2014, 7, 2900. [CrossRef]

12. Tan, G.; Shi, F.; Hao, S.; Zhao, L.-D.; Chi, H.; Zhang, X.; Uher, C.; Wolverton, C.; Dravid, V.P.; Kanatzidis, M.G. Non-equilibrium processing leads to record high thermoelectric figure of merit in PbTe-SrTe. Nat. Commun. 2016, 7, 12167. [CrossRef] [PubMed]

13. Heremans, J.P.; Jovovic, V.; Toberer, E.S.; Saramat, A.; Kurosaki, K.; Charoenphakdee, A.; Yamanaka, S.; Snyder, G.J. Enhancement of thermoelectric efficiency in PbTe by distortion of the electronic density of states. Science 2008, 321, 554-557. [CrossRef] [PubMed] 
14. Zhao, L.-D.; Lo, S.H.; Zhang, Y.S.; Sun, H.; Tan, G.J.; Uher, C.; Wolverton, C.; Dravid, V.P.; Kanatzidis, M.G. Ultralow thermal conductivity and high thermoelectric figure of merit in SnSe crystals. Nature 2014, 508, 373-377. [CrossRef] [PubMed]

15. Zhao, L.-D.; Tan, G.J.; Hao, S.Q.; He, J.Q.; Pei, Y.L.; Chi, H.; Wang, H.; Gong, S.K.; Xu, H.B.; Dravid, V.P.; et al. Ultrahigh power factor and thermoelectric performance in hole-doped single-crystal SnSe. Science 2016, 351, 141-144. [CrossRef] [PubMed]

16. Tan, G.J.; Shi, F.Y.; Hao, S.Q.; Chi, H.; Zhao, L.-D.; Uher, C.; Wolverton, C.; Dravid, V.P.; Kanatzidis, M.G. Codoping in SnTe: Enhancement of thermoelectric performance through synergy of resonance levels and band convergence. J. Am. Chem. Soc. 2015, 137, 5100-5112. [CrossRef] [PubMed]

17. Tan, G.J.; Shi, F.Y.; Hao, S.Q.; Chi, H.; Bailey, T.P.; Zhao, L.-D.; Uher, C.; Wolverton, C.; Dravid, V.P.; Kanatzidis, M.G. Valence band modification and high thermoelectric performance in SnTe heavily alloyed with MnTe. J. Am. Chem. Soc. 2015, 137, 11507-11516. [CrossRef] [PubMed]

18. Tan, G.; Shi, F.; Doak, J.W.; Sun, H.; Zhao, L.-D.; Wang, P.; Uher, C.; Wolverton, C.; Dravid, V.P.; Kanatzidis, M.G. Extraordinary role of hg in enhancing the thermoelectric performance of $p$-type SnTe. Energy Environ. Sci. 2015, 8, 267-277. [CrossRef]

19. Kim, S.I.; Lee, K.H.; Mun, H.A.; Kim, H.S.; Hwang, S.W.; Roh, J.W.; Yang, D.J.; Shin, W.H.; Li, X.S.; Lee, Y.H.; et al. Dense dislocation arrays embedded in grain boundaries for high-performance bulk thermoelectrics. Science 2015, 348, 109-114. [CrossRef] [PubMed]

20. Chung, D.-Y.; Hogan, T.; Brazis, P.; Rocci-Lane, M.; Kannewurf, C.; Bastea, M.; Uher, C.; Kanatzidis, M.G. $\mathrm{CsBi}_{4} \mathrm{Te}_{6}$ : A high-performance thermoelectric material for low-temperature applications. Science 2000, 287, 1024-1027. [CrossRef]

21. Venkatasubramanian, R.; Siivola, E.; Colpitts, T.; O'Quinn, B. Thin-film thermoelectric devices with high room-temperature figures of merit. Nature 2001, 413, 597-602. [CrossRef] [PubMed]

22. Biswas, K.; Zhao, L.-D.; Kanatzidis, M.G. Tellurium-free thermoelectric: The anisotropic $n$-type semiconductor $\mathrm{Bi}_{2} \mathrm{~S}_{3}$. Adv. Energy Mater. 2012, 2, 634-638. [CrossRef]

23. Wang, S.; Tan, G.; Xie, W.; Zheng, G.; Li, H.; Yang, J.; Tang, X. Enhanced thermoelectric properties of $\mathrm{Bi}_{2}\left(\mathrm{Te}_{1-x} \mathrm{Se}_{x}\right)_{3}$-based compounds as $n$-type legs for low-temperature power generation. J. Mater. Chem. 2012, 22, 20943-20951. [CrossRef]

24. Shi, X.; Kong, H.; Li, C.-P.; Uher, C.; Yang, J.; Salvador, J.R.; Wang, H.; Chen, L.; Zhang, W. Low thermal conductivity and high thermoelectric figure of merit in $n$-type $\mathrm{Ba}_{x} \mathrm{Yb}_{y} \mathrm{Co}_{4} \mathrm{Sb}_{12}$ double-filled skutterudites. Appl. Phys. Lett. 2008, 92, 182101. [CrossRef]

25. Tan, G.; Liu, W.; Chi, H.; Su, X.; Wang, S.; Yan, Y.; Tang, X.; Wong-Ng, W.; Uher, C. Realization of high thermoelectric performance in $p$-type unfilled ternary skutterudites $\mathrm{FeSb}_{2+x} \mathrm{Te}_{1-x}$ via band structure modification and significant point defect scattering. Acta Mater. 2013, 61, 7693-7704. [CrossRef]

26. Tan, G.; Zheng, Y.; Tang, X. High thermoelectric performance of nonequilibrium synthesized $\mathrm{CeFe}_{4} \mathrm{Sb}_{12}$ composite with multi-scaled nanostructures. Appl. Phys. Lett. 2013, 103, 183904. [CrossRef]

27. Tan, G.; Zheng, Y.; Yan, Y.; Tang, X. Preparation and thermoelectric properties of $p$-type filled skutteruditesCe $\mathrm{Fe}_{4-x} \mathrm{Ni}_{x} \mathrm{Sb}_{12}$. J. Alloys Compd. 2014, 584, 216-221. [CrossRef]

28. Tan, G.; Wang, S.; Li, H.; Yan, Y.; Tang, X. Enhanced thermoelectric performance in zinc substituted $p$-type filled skutterudites $\mathrm{CeFe}_{4-x} \mathrm{Zn}_{x} \mathrm{Sb}_{12}$. J. Solid State Chem. 2012, 187, 316-322. [CrossRef]

29. Liu, W.S.; Zhang, B.P.; Li, J.F.; Zhao, L.-D. Effects of SB compensation on microstructure, thermoelectric properties and point defect of $\mathrm{CoSb}_{3}$ compound. J. Phys. D Appl. Phys. 2007, 40, 6784-6790. [CrossRef]

30. Li, J.; Sui, J.; Barreteau, C.; Berardan, D.; Dragoe, N.; Cai, W.; Pei, Y.; Zhao, L.-D. Thermoelectric properties of Mg doped $p$-type BiCuSeO oxyselenides. J. Alloys Compd. 2013, 551, 649-653. [CrossRef]

31. Liu, Y.C.; Zheng, Y.H.; Zhan, B.; Chen, K.; Butt, S.; Zhang, B.P.; Lin, Y.H. Influence of Ag doping on thermoelectric properties of BiCuSeO. J. Eur. Ceram. Soc. 2015, 35, 845-849. [CrossRef]

32. Liu, Y.; Ding, J.; Xu, B.; Lan, J.; Zheng, Y.; Zhan, B.; Zhang, B.; Lin, Y.; Nan, C. Enhanced thermoelectric performance of La-doped BiCuSeO by tuning band structure. Appl. Phys. Lett. 2015, 106, 233903. [CrossRef]

33. Ren, G.K.; Butt, S.; Zeng, C.C.; Liu, Y.C.; Zhan, B.; Lan, J.L.; Lin, Y.H.; Nan, C.W. Electrical and thermal transport behavior in Zn-doped BiCuSeO oxyselenides. J. Electron. Mater. 2015, 44, 1627-1631. [CrossRef]

34. Farooq, M.U.; Butt, S.; Gao, K.W.; Zhu, Y.C.; Sun, X.G.; Pang, X.L.; Khan, S.U.; Mohmed, F.; Mahmood, A.; Mahmood, N.; et al. Cd-doping a facile approach for better thermoelectric transport properties of BiCuSeO oxyselenides. RSC Adv. 2016, 6, 33789-33797. [CrossRef] 
35. Han, M.K.; Jin, Y.S.; Yu, B.K.; Choi, W.; You, T.S.; Kim, S.J. Sulfur to oxygen substitution in BiCuSeO and its effect on the thermoelectric properties. J. Mater. Chem. A 2016, 4, 13859-13865. [CrossRef]

36. Tan, S.G.; Lei, H.C.; Shao, D.F.; Lv, H.Y.; Lu, W.J.; Huang, Y.N.; Liu, Y.; Yuan, B.; Zu, L.; Kan, X.C.; et al. Enhanced low temperature thermoelectric performance of Ag-doped BiCuSeO. Appl. Phys. Lett. 2014, 105, 082109.

37. Farooq, M.U.; Butt, S.; Gao, K.; Pang, X.L.; Sun, X.; Asfandiyar; Mohmed, F.; Ahmad, A.; Mahmood, A.; Mahmood, N. Improved thermoelectric performance of BiCuSeO byAg substitution at cu site. J. Alloys Compd. 2017, 691, 572-577. [CrossRef]

38. Zhang, M.; Yang, J.; Jiang, Q.; Fu, L.; Xiao, Y.; Luo, Y.; Zhang, D.; Cheng, Y.; Zhou, Z. Multi-role of sodium doping in BiCuSeO on high thermoelectric performance. J. Electron. Mater. 2015, 44, 2849-2855. [CrossRef]

39. Liu, Y.; Lan, J.; Zhang, B.; Lin, Y.; Nan, C. Thermoelectric transport properties of BiCuSeO with embedded $\mathrm{La}_{0.8} \mathrm{Sr}_{0.2} \mathrm{CoO}_{3}$ nanoinclusions. Sci. China Technol. Sci. 2016, 59, 1036-1041. [CrossRef]

40. Liu, Y.C.; Zhou, Y.M.; Lan, J.L.; Zeng, C.C.; Zheng, Y.H.; Zhan, B.; Zhang, B.P.; Lin, Y.H.; Nan, C.W. Enhanced thermoelectric performance of $\mathrm{BiCuSeO}$ composites with nanoinclusion of $\mathrm{Cu}$ selenides. J. Alloys Compd. 2016, 662, 320-324. [CrossRef]

41. Ren, G.-K.; Lan, J.-1.; Butt, S.; Ventura, K.J.; Lin, Y.-H.; Nan, C.-W. Enhanced thermoelectric properties in $\mathrm{Pb}$-doped BiCuSeO oxyselenides prepared by ultrafast synthesis. RSC Adv. 2015, 5, 69878-69885. [CrossRef]

42. Yang, D.; Su, X.; Yan, Y.; Hu, T.; Xie, H.; He, J.; Uher, C.; Kanatzidis, M.G.; Tang, X. Manipulating the combustion wave during self-propagating synthesis for high thermoelectric performance of layered oxychalcogenide $\mathrm{Bi}_{1-x} \mathrm{~Pb}_{x} \mathrm{CuSeO}$. Chem. Mater. 2016, 28, 4628-4640. [CrossRef]

43. Lan, J.L.; Liu, Y.C.; Zhan, B.; Lin, Y.H.; Zhang, B.; Yuan, X.; Zhang, W.; Xu, W.; Nan, C.W. Enhanced thermoelectric properties of Pb-doped BiCuSeO ceramics. Adv. Mater. 2013, 25, 5086-5090. [CrossRef] [PubMed]

44. Wang, J.Y.; Zhou, Y.C.; Lin, Z.J. Mechanical properties and atomistic deformation mechanism of $\gamma-\mathrm{Y}_{2} \mathrm{Si}_{2} \mathrm{O}_{7}$ from first-principles investigations. Acta Mater. 2007, 55, 6019-6026. [CrossRef]

45. Dong, S.T.; Lv, Y.Y.; Zhang, B.B.; Zhang, F.; Yao, S.H.; Chen, Y.B.; Zhou, J.; Zhang, S.T.; Gu, Z.B.; Chen, Y.F. Strong correlation of the growth mode and electrical properties of $\mathrm{BiCuSeO}$ single crystals with growth temperature. Crystengcomm 2015, 17, 6136-6141. [CrossRef]

46. Wu, X.; Wang, J.-L.; Zhang, H.; Wang, S.; Zhai, S.; Li, Y.; Elhadj, D.; Fu, G. Epitaxial growth and thermoelectric properties of $c$-axis oriented $\mathrm{Bi}_{1-x} \mathrm{~Pb}_{x} \mathrm{CuSeO}$ single crystalline thin films. Crystengcomm 2015, 17, 8697-8702. [CrossRef]

47. Samanta, M.; Guin, S.N.; Biswas, K. Ultrathin few layer oxychalcogenide BiCuSeO nanosheets. Inorg. Chem. Front. 2017, 4, 84-90. [CrossRef]

48. Saha, S.K.; Dutta, G. Elastic and thermal properties of the layered thermoelectrics BiCuSeO and LaOCuSe. Phys. Rev. B 2016, 94, 125209. [CrossRef]

49. Liu, G.; Sun, H.Y.; Zhou, J.; Li, Q.F.; Wan, X.G. Thermal properties of layered oxychalcogenides BiCuOCh (Ch $=\mathrm{S}$, Se, and Te): A first-principles calculation. J. Appl. Phys. 2016, 119, 185109. [CrossRef]

50. Ji, H.S.; Togo, A.; Kaviany, M.; Tanaka, I.; Shim, J.H. Low phonon conductivity of layered BiCuSO, BiCuSeO, and BiCuTeO from first principles. Phys. Rev. B 2016, 94, 115203. [CrossRef]

51. Shao, H.; Tan, X.; Liu, G.-Q.; Jiang, J.; Jiang, H. A first-principles study on the phonon transport in layered bicuose. Sci. Rep. 2016, 6, 21035. [CrossRef] [PubMed]

52. Hsiao, C.-L.; Qi, X. The oxidation states of elements in pure and Ca-doped BiCuSeO thermoelectric oxides. Acta Mater. 2016, 102, 88-96. [CrossRef]

53. Chou, T.-L.; Tewari, G.C.; Chan, T.-S.; Hsu, Y.-Y.; Yamauchi, H.; Karppinen, M. Exafs study of thermoelectric BiCuOSe: Effects of Cu vacancies. Solid State Commun. 2015, 206, 12-16. [CrossRef]

54. Berthebaud, D.; Guilmeau, E.; Lebedev, O.I.; Maignan, A.; Gamon, J.; Barboux, P. The BiCu $\mathrm{B}_{1-x} \mathrm{OS}_{\text {oxysulfide: }}$ $\mathrm{Cu}$ deficiency and electronic properties. J. Solid State Chem. 2016, 237, 292-299. [CrossRef]

55. Li, F.; Wei, T.R.; Kang, F.Y.; Li, J.F. Thermal stability and oxidation resistance of BiCuSeO based thermoelectric ceramics. J. Alloys Compd. 2014, 614, 394-400. [CrossRef]

56. Barreteau, C.; Berardan, D.; Dragoe, N. Studies on the thermal stability of BiCuSeO. J. Solid State Chem. 2015, 222, 53-59. [CrossRef]

57. Ding, J.; Xu, B.; Lin, Y.; Nan, C.; Liu, W. Lattice vibration modes of the layered material BiCuSeO and first principles study of its thermoelectric properties. New J. Phys. 2015, 17, 083012. [CrossRef] 
58. Saha, S.K. Exploring the origin of ultralow thermal conductivity in layered BiOCuSe. Phys. Rev. B 2015, 92, 041202. [CrossRef]

59. Vaqueiro, P.; Al Orabi, R.A.; Luu, S.D.; Guelou, G.; Powell, A.V.; Smith, R.I.; Song, J.P.; Wee, D.; Fornari, M. The role of $\mathrm{Cu}$ in the thermal conductivity of thermoelectric oxychalcogenides: Do lone pairs matter? Phys. Chem. Chem. Phys. 2015, 17, 31735-31740. [CrossRef] [PubMed]

60. Abrahams, S.C. Piezoelectric nonlinear optic $\mathrm{CuGaSe}_{2}$ and $\mathrm{CdGeAs}_{2}$ : Crystal structure, chalcopyrite microhardness, and sublattice distortion. J. Chem. Phys. 1974, 61, 1140. [CrossRef]

61. Sales, B.C.; Mandrus, D.G.; Chakoumakos, B.C. Chapter 1 use of atomic displacement parameters in thermoelectric materials research. In Semiconductors and Semimetals; Terry, M.T., Ed.; Elsevier: Amsterdam, The Netherlands, 2001; Volume 70, pp. 1-36.

62. Kumar, S.; Schwingenschlogl, U. Lattice thermal conductivity in layered BiCuSeO. Phys. Chem. Chem. Phys. 2016, 18, 19158-19164. [CrossRef] [PubMed]

63. Barreteau, C.; Berardan, D.; Amzallag, E.; Zhao, L.-D.; Dragoe, N. Structural and electronic transport properties in Sr-doped BiCuSeO. Chem. Mat. 2012, 24, 3168-3178. [CrossRef]

64. Mizuno, S.; Ishizawa, M.; Fujishiro, H.; Naito, T.; Katsui, H.; Goto, T. Ball milling effects for induced carriers and reduced grain size on thermoelectric properties in $\mathrm{Bi}_{1-x} \mathrm{Sr}_{x} \mathrm{CuSeO}(x=0,0.1)$. Jpn. J. Appl. Phys. 2016, 55, 11. [CrossRef]

65. Feng, D.; Zheng, F.S.; Wu, D.; Wu, M.H.; Li, W.; Huang, L.; Zhao, L.-D.; He, J.Q. Investigation into the extremely low thermal conductivity in Ba heavily doped BiCuSeO. Nano Energy 2016, 27, 167-174. [CrossRef]

66. Tan, G.J.; Zhao, L.-D.; Kanatzidis, M.G. Rationally designing high-performance bulk thermoelectric materials. Chem. Rev. 2016, 116, 12123-12149. [CrossRef] [PubMed]

(C) 2017 by the authors; licensee MDPI, Basel, Switzerland. This article is an open access article distributed under the terms and conditions of the Creative Commons Attribution (CC BY) license (http:/ / creativecommons.org/licenses/by/4.0/). 